\title{
The Handling of Immunoreactive Vasopressin by the Isolated Perfused Rat Kidney
}

\author{
Ralph Rabkin, Leonard Share, Paul A. Payne, Judy Young, and Joan Crofton, \\ Departments of Medicine and Physiology and Biophysics, University of Tennessee \\ Center for the Health Sciences, Memphis, Tennessee 38163
}

A B S T RA C T Using the isolated rat kidney perfused with an artificial medium containing glucose as the sole fuel, we studied the renal handling of immunoreactive arginine vasopressin (AVP) and determined the effect of various factors on the ability of the kidney to remove AVP.

In control kidneys perfused with AVP at concentrations below $116 \mu \mathrm{U} / \mathrm{ml}$, the organ clearance of AVP $\left(\mathrm{OC}_{\mathrm{AVP}}\right)$ was $1,145 \pm 47(\mathrm{SE}) \mu \mathrm{l} / \mathrm{min}$, whereas glomerular filtration rate (GFR) averaged $515 \pm 37 \mu \mathrm{l} / \mathrm{min}$. Filtration could thus account for up to $45 \%$ of the $\mathrm{OC}_{\mathrm{AVP}}$, the balance presumably being cleared from the peritubular circulation. Of the AVP filtered, only $38 \%$ could be recovered in the urine (urinary clearance AVP averaged $205 \pm 12 \mu \mathrm{l} / \mathrm{min}$ ) suggesting that the balance was taken up by the tubular epithelium and degraded. Fractional excretion of filtered AVP rose significantly in the presence of anoxia and cold $\left(10^{\circ} \mathrm{C}\right)$ to 49 and $59 \%$, respectively, but was not affected by ouabain or high levels of AVP $(458 \pm 58 \mu \mathrm{U} / \mathrm{ml})$.

The $\mathrm{OC}_{\mathrm{AVP}}$ was not significantly altered by the absence of glucose in the perfusate, anoxia, or ureteral ligation, maneuvers that were associated with significant reductions in GFR. In these and the control experiments, there was a significant inverse correlation between GFR and peritubular clearance emphasizing the importance of the latter $(r=-0.749 ; P<0.001)$. Cold, ouabain, and high concentrations of AVP reduced the clearance of AVP by the kidneys.

On the basis of these studies we conclude that the kidney clears AVP from the circulation via two path-

Portions of this work were presented at the International Conference on the Neurohypophysis, Key Biscayne, Fla., November 1976; the Southern Society of Clinical Investigation, New Orleans, La., January 1977; and the Annual Meeting of the Endocrine Society, Chicago, Ill., June 1977.

Address reprint requests to Dr. R. Rabkin, Nephrology Division, Stanford University School of Medicine, Stanford, Calif. 94305.

Received for publication 22 September 1977 and in revised form 18 September 1978. ways, glomerular clearance and peritubular clearance. This exposes both the luminal and contraluminal surfaces of the tubular cells to the hormone, allowing these cells to remove AVP from the filtrate and the peritubular compartment. Noteworthy is the observation that under several conditions when GFR falls reducing the glomerular clearance of AVP, peritubular clearance increases and the total clearance of AVP by the kidney remains constant.

\section{INTRODUCTION}

The kidney plays an important role in regulating the plasma levels of several peptide hormones including vasopressin. This is achieved in part by degradation and in part by excretion of the hormone in the urine. In addition to being the target organ for the action of vasopressin, the kidney avidly removes this peptide from the circulation and accounts for between onethird and one-half of its metabolic clearance rate (1). Despite several studies (1), confusion exists as to the exact manner in which the kidney handles vasopressin. This is in part the consequence of insensitive bioassay procedures, the rapid half disappearance time of the hormone, and the variable design of earlier studies.

The purpose of the present study, carried out with isolated perfused rat kidneys, was to assess the manner in which the kidney handles immunoreactive arginine vasopressin (AVP) ${ }^{1}$ and to determine which of several metabolic factors might affect this process. The isolated kidney perfused with a continuously recirculated electrolyte-albumin solution was chosen as the experimental model for several reasons. First, it has a perfusion flow about six times that of the normal in vivo renal blood flow, which in the presence of a glomerular filtration rate roughly one-half that in vivo may tend

${ }^{1}$ Abbreviations used in this paper: AVP, arginine vasopressin; GFR, glomerular filtration rate; $\mathrm{OC}_{\mathrm{AVP}}$, organ clearance of AVP. 
to exaggerate processes occurring on the contraluminal side of the tubular cell, thus facilitating their study. Second, with a bloodless perfusion medium various extraction procedures necessary for the assay of vasopressin are avoided, and the precision of the assay is thus increased. Third, various maneuvers may be performed with the isolated kidney that are impossible to carry out in vivo.

\section{METHODS}

The study was carried out with male Sprague-Dawley rats weighing 250-350 $\mathrm{g}$ and allowed free access to food and water. Anesthesia was produced with intraperitoneal pentobarbital $(60 \mathrm{mg} / \mathrm{kg})$. The kidneys were then isolated and perfused according to the method of Nishiitsutsuji-Uwo et al. (2) as modified by Ross et al. (3). After an intravenous injection of mannitol, $50 \mathrm{mg} / 100 \mathrm{~g}$, the abdomen was opened by a midline incision and the right ureter was catheterized with polyethylene-10 tubing. Heparin (200 U) was administered intravenously and a thin glass cannula was inserted into the superior mesenteric artery and then into the aorta. The perfusion flow was started and the glass cannula was then inserted into the right renal artery after which the kidney was rapidly excised and placed in the perfusion apparatus. The renal vein was not cannulated. The kidneys were perfused with a Watson Marlow MHRE3 pulsatile flow pump (WatsonMarlow Ltd., Cornwall, England). After a period of equilibration, perfusion pressure was maintained at an effective maximum pressure of $100 \mathrm{~mm} \mathrm{Hg}$ unless otherwise stated. The perfusion apparatus was housed in a plexiglass cabinet and the temperature was maintained at $37^{\circ} \mathrm{C}$. The perfusion medium (3) consisted of a modified Krebs-Henseleit bicarbonate solution containing $6.7 \mathrm{~g}$ of albumin per $100 \mathrm{ml}$, gassed continuously with $95 \%$ oxygen and $5 \% \mathrm{CO}_{2}$. Bovine serum albumin (Fraction V, Miles Laboratories, Inc., Elkhart, Ind.) was dissolved in $860 \mathrm{ml}$ of Krebs-Henseleit bicarbonate to which $40 \mathrm{ml}$ of $1 \mathrm{M}$ sodium bicarbonate was added; this was dialysed at $4^{\circ} \mathrm{C}$ against six to eight changes of Krebs-Henseleit bicarbonate for $72 \mathrm{~h}$. The final medium contained in millimoles per liter, sodium 143 , potassium 5 , calcium 2.25 , magnesium 1.18 , bicarbonate 18 , chloride 116 , phosphate 1.2 , sulfate 0.8 , and glucose $5 \mathrm{mM}$ at $\mathrm{pH} 7.4$ when gassed with $5 \% \mathrm{CO}_{2}$.

$4 \mathrm{~min}$ after the start of the perfusion $\left[{ }^{14} \mathrm{C}\right]$ carboxyl-inulin (Amersham/Searle Corp., Arlington Heights, Ill.) was added to the medium and a control perfusate sample was obtained. At $10 \mathrm{~min}$ synthetic arginine vasopressin (Bachem, Torrance, Calif.; $380 \mathrm{U} / \mathrm{mg}$ ) was added to achieve concentrations ranging from 35 to $116 \mu \mathrm{U} / \mathrm{ml}$ in the initial perfusate sample obtained at $20 \mathrm{~min}$. After allowing $15 \mathrm{~min}$ from the start of the perfusion for the stabilization of renal function, seven 10 -min urine collections with midpoint perfusate samples $(1.2 \mathrm{ml})$ were obtained. In some experiments the kidneys were then removed from the perfusion apparatus and further perfusate samples were obtained. The volume of perfusion medium at the start of midpoint sampling was $\cong 63 \mathrm{ml}$; sample volumes removed were not replaced. To avoid loss of AVP by adherence to glass, urine samples were collected in tubes that had been lightly coated with albumin and allowed to dry.

Experimental groups. The kidneys were perfused under several different conditions: (a) Six kidneys were perfused under standard conditions referred to as controls. (b) Six kidneys were perfused with a glucose-free medium. (c) Four kidneys were studied under anoxic conditions. This was achieved by gassing the medium with $95 \%$ nitrogen and $5 \%$
$\mathrm{CO}_{2}$. (d) Four kidneys were perfused with ouabain (4 mM) added to the medium before starting the perfusion. (e) Four kidneys were perfused in the presence of high levels of AVP $(458 \pm 58 \mu \mathrm{U} / \mathrm{ml})$. $(f)$ Four kidneys were perfused with cold $\left(10^{\circ} \mathrm{C}\right)$ medium by circulating cold water through a glass jacket surrounding the oxygenator. $(\mathrm{g})$ Obstruction of the ureter of four kidneys was achieved by clamping the ureteral catheter 5 min before collecting the first perfusate sample.

Binding of AVP to albumin was assessed by ultrafiltration studies employing a Diaflo XM50 membrane in an Amicon Model TCF10 ultrafiltration system (Amicon Corp., Lexington, Mass.). Ultrafiltration of AVP added to freshly prepared medium was compared with that of AVP added to Krebs-Henseleit bicarbonate. The two solutions were gassed with $95 \%$ $\mathrm{O}_{2}$ and $5 \% \quad \mathrm{CO}_{2}$ before ultrafiltration, and the ultrafiltration system was pressurized with the same gas mixture. The temperature was maintained at $37^{\circ} \mathrm{C}$ by placing the apparatus in the kidney perfusion cabinet. At the end of 18 min of ultrafiltration, samples of retentate and ultrafiltrate were obtained and assayed for AVP.

Analytical methods. Arginine vasopressin was determined in unextracted perfusate and urine samples by means of a radioimmunoassay as previously described (4). The antibody used in the immunoassay did not cross-react with lysine vasopressin, arginine vasotocin, oxytocin or angiotensins I and II. Between-assay coefficient of variation $(n=21)$ was $8.9 \%$ and the within-assay coefficient of variation based on five assays was $7.3 \pm 1.4 \%$ (SE). Extraction procedures were not used, as recovery of AVP added to medium averaged 94 $\pm 1.81 \%$, whereas recovery of AVP added to urine averaged $94.7 \pm 2.1 \%$. Concentrations were not corrected for incomplete recovery. Sodium was measured with an IL 143 flame photometer (Instrumentation Laboratory, Inc., Lexington, Mass.). $\left[{ }^{14} \mathrm{C}\right]$ carboxyl-inulin was counted in a Nuclear Chicago Isocap 300 liquid scintillating counter (Nuclear Chicago, Chicago, Ill.).

Calculations. In each experiment the organ clearance of AVP $\left(\mathrm{OC}_{\mathrm{AVP}}\right)$, which represents the volume of perfusate from which AVP is completely and irreversibly removed each minute, was calculated between successive 10 -min samples according to Mortimore et al. (5) as $\mathrm{OC}_{\mathrm{AvP}}=2.3 \mathrm{~V} / \Delta \mathrm{t} \log \left(\left[\mathrm{C}_{1}\right.\right.$ $\left.\left.-C_{\alpha}\right] /\left[C_{2}-C_{\alpha}\right]\right)$, where $V=$ volume of perfusion fluid corrected for perfusate sampling; $C_{1}$ and $C_{2}=$ initial and final concentrations over time interval $t$; and $\mathrm{C}_{\alpha}=$ asymptote approached by $C$ after prolonged perfusion. $C_{\alpha}$ was taken as zero because prolonged perfusion at low concentrations of AVP indicated the eventual disappearance of the peptide. Use of this formula was validated by the finding that $(a)$ the disappearance of AVP from the medium followed approximately first order kinetics (Fig. 1A), and (b) the clearance of $\left[{ }^{14} \mathrm{C}\right]$ inulin determined by this formula was similar to the clearance as determined by the standard urine clearance formula described below (in the control experiments these clearance values were $515 \pm 37$ and $545 \pm 37 \mu \mathrm{l} / \mathrm{min}$, respectively; $P$ $>0.05$, Student's paired $t$ test). Based on the assumption that AVP is freely filtered at the glomerulus and that none of the filtered hormone is reabsorbed intact into the peritubular circulation, the glomerular clearance of AVP was taken to equal the glomerular filtration rate, and the peritubular clearance was taken to equal the difference between the organ clearance and the glomerular clearance of AVP.

The urinary clearance of $\left[{ }^{14} \mathrm{C}\right]$ carboxyl-inulin and of AVP were calculated from the urine:plasma concentration ratios and the urine flow. The clearance of $\left[{ }^{14} \mathrm{C}\right]$ inulin was used as a measure of glomerular filtration rate (GFR). Fractional excretion of filtered AVP was calculated as the urinary AVP clearance/GFR $\times 100$ and fractional excretion of filtered sodium as sodium clearance/GFR $\times 100$. Perfusion flow was determined 


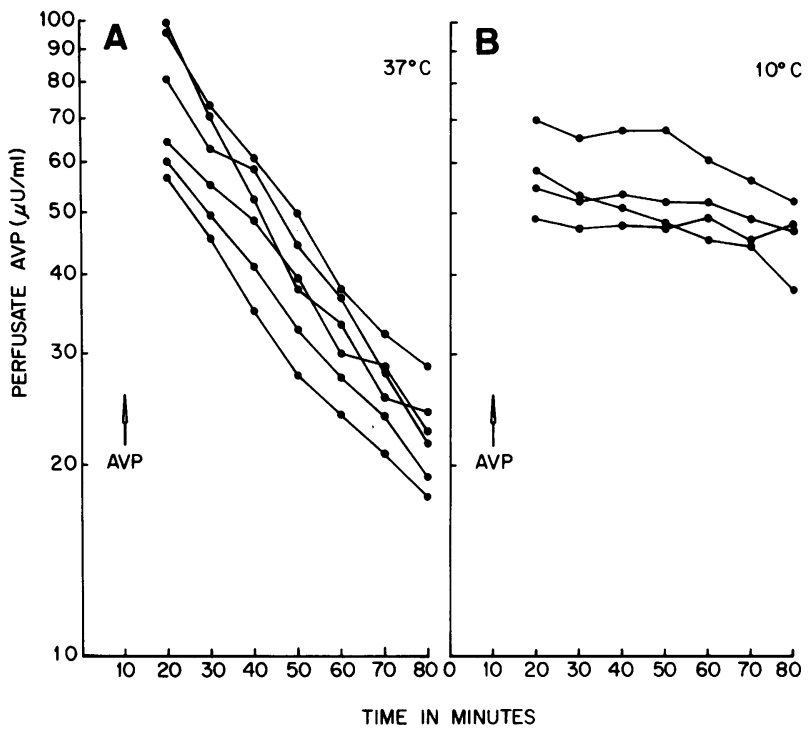

Figure 1 (A) Disappearance of AVP from the perfusion medium of control kidneys perfused at $37^{\circ} \mathrm{C}$. (B) Disappearance of AVP from the perfusion medium of kidneys perfused at $10^{\circ} \mathrm{C}$.

from the rate at which renal venous effluent filled a funnelshaped siphon held continuously in place below the kidney.

The average of all the measured values in each experiment was taken as the value for that experiment. Results are expressed as the mean \pm SEM. The data were statistically analyzed (6) with a one-way analysis of variance, and if the $F$ ratio was significant, Duncan's new multiple range test was used to make comparisons among all the means. A level of $P<0.05$ was regarded as significant. Student's $t$ test for nonpaired data was used to evaluate the ultrafiltration data. Regression analysis was performed by the method of least squares.

\section{RESULTS}

\section{Albumin binding studies}

Ultrafiltration of medium containing AVP through a Diaflo XM 50 membrane yielded an AVP concentration ratio of ultrafiltrate to retentate of $0.78 \pm 0.07$ ( $n$ $=4$ ). This did not differ significantly from the AVP concentration ratio of $0.75 \pm 0.01(n=4)$ achieved with ultrafiltration of Krebs-Henseleit bicarbonate containing AVP, indicating that significant binding of AVP to bovine serum albumin does not occur.

\section{Perfusion studies}

The organ clearance of AVP (Table I). In control kidneys the organ clearance of AVP, determined from its rate of disappearance from the perfusate, averaged $1,145 \pm 47 \mu \mathrm{l} / \mathrm{min}$. As shown in Fig. 1A the disappearance of AVP followed approximately first order kinetics. In several experiments, to exclude the possibility that the disappearance of AVP was a result of spon- taneous degradation or to degradation by enzymes released from the kidney, several samples of perfusate were obtained after removing the kidneys from the circuit. In the absence of the kidney, no decrease in AVP concentration occurred (Fig. 2).

In kidneys perfused without glucose in the medium, the $\mathrm{OC}_{\mathrm{AvP}}$ was $983 \pm 53 \mu \mathrm{l} / \mathrm{min}$, a value not significantly different from the control group. Similarly, the ${ } C_{A v P}$ was not significantly altered when kidneys were perfused under anoxic conditions $(1,037 \pm 66 \mu \mathrm{l} / \mathrm{min})$, nor when the ureters were obstructed $(992 \pm 50 \mu \mathrm{l} / \mathrm{min})$.

Addition of ouabain to the medium was associated with a significant drop in the $\mathrm{OC}_{\mathrm{AVP}}(866 \pm 60 \mu \mathrm{l} / \mathrm{min})$ as compared to the control value. Similarly, high levels of AVP (initial concentration 315-592 $\mu \mathrm{U} / \mathrm{ml}$ ) significantly depressed the $\mathrm{OC}_{\mathrm{AVP}}(877 \pm 69 \mu \mathrm{l} / \mathrm{min})$. Cooling the kidney to $10^{\circ} \mathrm{C}$ greatly reduced the ability of the kidney to remove AVP from the perfusate (Fig. 1B). In these experiments the organ clearance of AVP was calculated on the assumption that $\mathrm{C} \alpha$ equals zero in the cold. Thus the value obtained, $204 \pm 63 \mu \mathrm{l} / \mathrm{min}$, should be regarded as an approximation, particularly as the fall in perfusate AVP concentration was small, introducing some error into the calculation. GFR dropped significantly to $199 \pm 33 \mu \mathrm{l} / \mathrm{min}$. From these data it appears that peritubular clearance was essentially abolished in the cold and that AVP was being removed by glomerular filtration, a process dependent on mechanical energy.

Contribution of glomerular clearance (assumed to

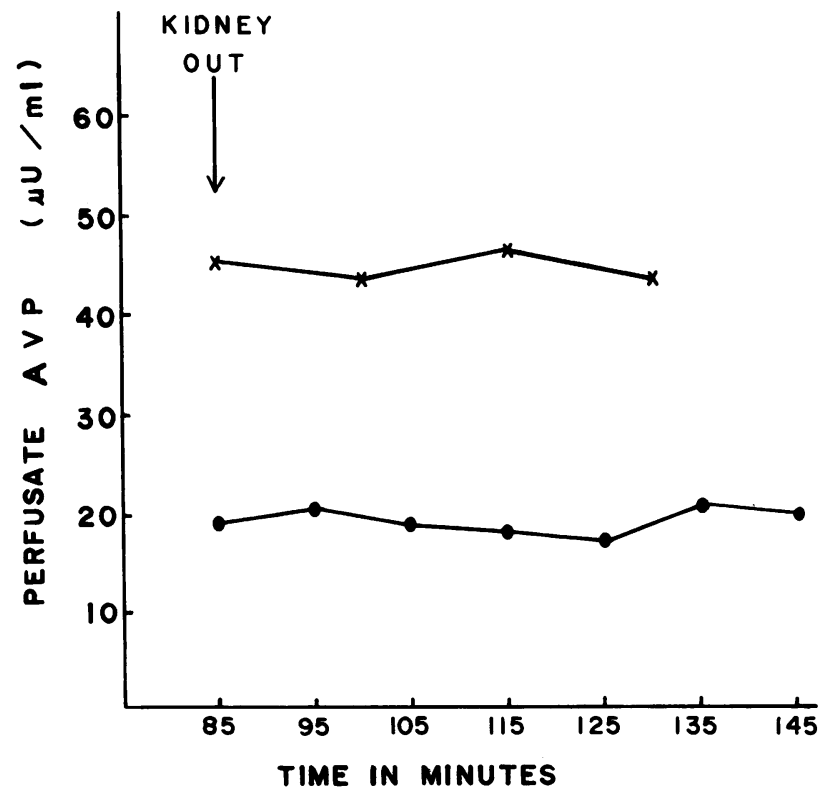

FIGURE 2 Effect of removing the kidney from the perfusion circuit on the disappearance of AVP from the medium of a control $(\Theta)$ and an anoxic $(x)$ kidney. Kidneys were removed after 85 min of perfusion. 
TABLE I

Function* in Isolated Rat Kidneys Perfused under Different Conditions with AVP $(74.8 \pm 4.5 \mu \mathrm{U} / \mathrm{ml})$

\begin{tabular}{|c|c|c|c|c|c|c|c|}
\hline $\begin{array}{l}\text { No. of experiments } \ldots \ldots \ldots \ldots \\
\text { Effective maximum perfusion } \\
\text { pressure. } m m \mathrm{Hg} \ldots \ldots \ldots \ldots\end{array}$ & $\begin{array}{c}\text { Control } \\
6 \\
100\end{array}$ & $\begin{array}{c}\text { Glucose-free } \\
\text { medium } \\
6 \\
100\end{array}$ & $\begin{array}{c}\text { Anoxia } \\
4 \\
100\end{array}$ & $\begin{array}{c}\text { Ouabain } \\
(4 \mathrm{mM}) \\
4 \\
100\end{array}$ & $\begin{array}{c}\text { High level } \\
\text { AVP } \\
(458 \pm 58 \\
\mu \mathrm{U} / \mathrm{ml}) \\
4 \\
100\end{array}$ & $\begin{array}{c}\text { Cold }\left(10^{\circ} \mathrm{C}\right) \\
4 \\
190\end{array}$ & $\begin{array}{c}\text { Obstruction } \\
4 \\
100\end{array}$ \\
\hline $\mathrm{OC}_{\mathrm{AVP}}, \mu l / \min$ & $1,145 \pm 47$ & $983 \pm 53$ & $1,037 \pm 66$ & $866 \pm 60 \ddagger$ & $877 \pm 69$ & $(\sim 204)( \pm 63) \S$ & $992 \pm 50$ \\
\hline $\mathrm{UC}_{\mathrm{AVP}}, \mu l / \mathrm{min}$ & $205 \pm 12$ & $130 \pm 19 t$ & $48 \pm 7 \ddagger$ & $75 \pm 5 \ddagger$ & $212 \pm 12$ & $113 \pm 13 \ddagger$ & - \\
\hline $\mathrm{PC} / \mathrm{OC}_{\mathrm{AVP}}, \%$ & $54.6 \pm 3.8$ & $73.7 \pm 2.8 \ddagger$ & $91.7 \pm 1.1 \ddagger$ & $77.2 \pm 1.9 \ddagger$ & $43.5 \pm 5.1 \ddagger$ & - & - \\
\hline $\mathrm{GC} / \mathrm{OC}_{\mathrm{AVP}}, \%$ & $45.4 \pm 3.8$ & $26.3 \pm 2.8 \ddagger$ & $8.3 \pm 1.1 \ddagger$ & $22.8 \pm 1.9 \ddagger$ & $56.5 \pm 5.1 \ddagger$ & - & - \\
\hline $\mathrm{UC} / \mathrm{GC}_{\mathrm{AVP}}=\mathrm{FE}_{\mathrm{AVP}}, \%$ & $38.1 \pm 2.6$ & $44.9 \pm 1.9$ & $49.1 \pm 2.6$ & $34.1 \pm 1.8$ & $45.3 \pm 2.1$ & $59.2 \pm 5.3 \ddagger$ & - \\
\hline $\mathrm{FE}_{\mathrm{NA}}, \%$ & $8.2 \pm 0.8$ & $26.8 \pm 1.6 \sharp$ & $62.8 \pm 3.3 \ddagger$ & $35.6 \pm 1.8 \ddagger$ & $12.2 \pm 2.0$ & $78.5 \pm 4.7 \ddagger$ & - \\
\hline
\end{tabular}

Abbreviations used in this table: AVP, arginine vasopressin; $O_{A V P}$, organ clearance of AVP; GFR, glomerular filtration rate; $\mathrm{GC}_{\mathrm{AVP}}=$ glomerular clearance of AVP; $\mathrm{PC}_{\mathrm{AVP}}$, peritubular clearance of $\mathrm{AVP} ; \mathrm{UC}_{\mathrm{AVP}}$, urinary clearance AVP; FE fractional excretion of filtered AVP; $\mathrm{FE}_{\mathrm{NA}}$, fractional excretion of filtered sodium; RPF, renal perfusion flow.

* Values are means \pm SEM.

\$ Significantly different when compared to controls using Duncan's new multiple range test with $P<0.05$.

$\S$ This value is an approximation and thus has not been compared statistically with the controls.

equal GFR) and peritubular clearance to the organ clearance of AVP (Table I, Fig. 3). In control kidneys, GFR $(515 \pm 37 \mu \mathrm{l} / \mathrm{min})$ was $45.4 \pm 3.8 \%$ of the $\mathrm{OC}_{\text {Avp. }}$ In the absence of glucose, GFR fell to $262 \pm 40 \mu \mathrm{l} / \mathrm{min}$, which was $26.3 \pm 2.8 \%$ of the $\mathrm{OC}_{\mathrm{AvP}}$, and in the presence of anoxia GFR fell to $87 \pm 14 \mu \mathrm{l} / \mathrm{min}$, being $8.3 \pm 1.1 \%$ of the $\mathrm{OC}_{\mathrm{AVp}}$. Under both these conditions, despite a significant fall in GFR, the $\mathrm{OC}_{\mathrm{AvP}}$ remained essentially unchanged from the control values because of an increase in peritubular clearance (Table I, Fig. 3). In the control, glucose-free, and anoxic kidneys, there was a significant inverse correlation $(P<0.001 ; r=-0.749)$ between the glomerular and peritubular clearance of AVP (Fig. 3). Although the GFR was not measured in the obstructed kidneys, it is reasonable to assume that it was severely reduced. Nevertheless, the $\mathrm{OC}_{\mathrm{Avp}}$ was not found to differ from the control values. Presumably, under these circumstances AVP was being removed almost entirely by peritubular clearance.

In kidneys perfused with high levels of AVP, there was a significant fall in $O C_{A v P}$ despite maintenance of GFR at a level $(485 \pm 7 \mu \mathrm{l} / \mathrm{min})$ similar to the control values. This would suggest that the rate of filtration of AVP was maintained and that the fall in $\mathrm{OC}_{\mathrm{AVP}}$ was a consequence of a depressed rate of clearance from the peritubular circulation. In fact, peritubular clearance in these kidneys was significantly lower than in the control group $(392 \pm 74 \mu \mathrm{l} / \mathrm{min}$ vs. $631 \pm 66 \mu \mathrm{l} / \mathrm{min})$. In the ouabain perfused kidneys, the decrease in $\mathrm{OC}_{\mathrm{AVP}}$ could be accounted for by the significant fall in GFR (195 $\pm 9 \mu \mathrm{l} / \mathrm{min})$.
Fractional excretion of filtered AVP and sodium (Table I). In control kidneys, the fractional excretion of filtered AVP was $38.1 \pm 2.6 \%$, and the fractional excretion of sodium was $8.2 \pm 0.8 \%$. Expressing the results in the control kidneys in a different manner, it can be calculated (urinary clearance AVP/OC $\mathrm{OVP}_{\mathrm{AV}}$ ) that urinary excretion of AVP accounted for $17.9 \pm 0.9 \%$ of all the immunoreactive AVP removed by the kidney. In glucosefree perfusions, the glomerular clearance and urinary clearance of AVP fell proportionately, hence fractional excretion of filtered AVP $(44.9 \pm 1.9 \%)$ did not differ significantly from that of the controls; fractional excretion of filtered sodium $(26.8 \pm 1.6 \%)$ did, however, increase significantly. Similarly, in ouabain-treated kidneys fractional excretion of filtered AVP $(34.1 \pm 1.8 \%)$ was not increased, whereas there was a significant increase in the fractional excretion of sodium (35.6 $\pm 1.8 \%$ ). Anoxia was associated with a proportionately greater fall in GFR than in urinary clearance of AVP or sodium resulting in a significant increase in the calculated fractional excretion of filtered AVP $(49.1 \pm 2.6 \%)$ and filtered sodium $(62.8 \pm 3.3 \%)$. Cold perfusions were also associated with a significant increase in the fractional excretion of AVP $(59.2 \pm 5.3 \%)$ and of sodium $(78.5 \pm 4.7 \%)$. In kidneys perfused with high levels of AVP there was an insignificant rise in the fractional excretion of AVP $(45.3 \pm 2.1 \%)$ and of sodium (12.2 $\pm 2.0 \%)$ as compared to the controls.

Renal perfusion flow (Table I). Except for the cold group, perfusion flow in the different treatment groups did not differ significantly from control values (37.9 


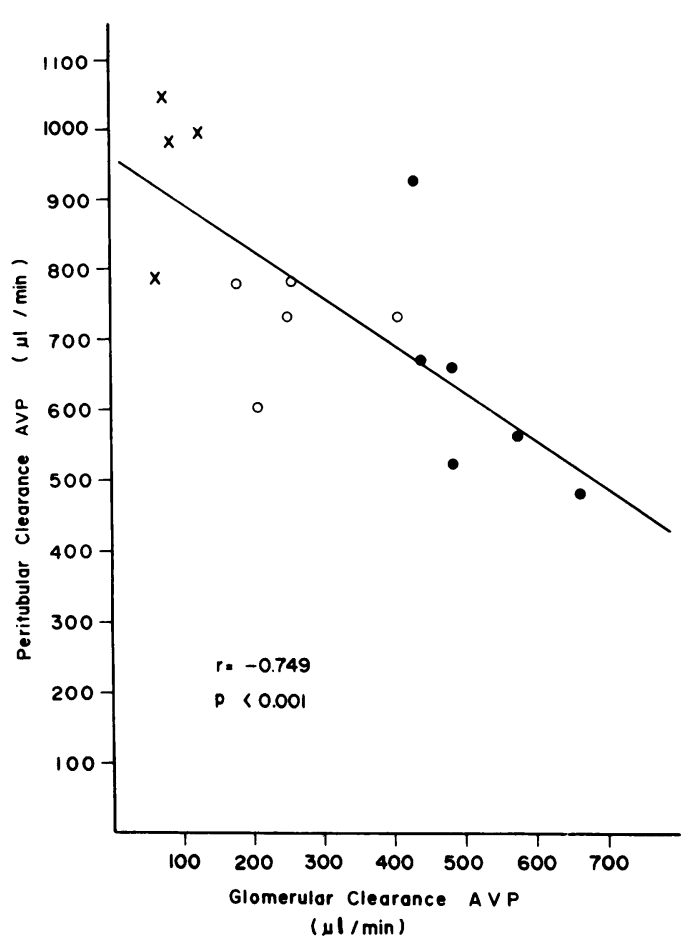

FIGURE 3 Relationship between peritubular clearance and glomerular clearance of AVP. The latter has been assumed to be equal to the GFR and the former has been calculated as being equal to the difference between the organ clearance of vasopressin and GFR. The calculated regression line for values from control $(\Theta)$, glucose-free $(O)$, and anoxic $(x)$ kidneys has been drawn $(y=960.74-0.68 x)$. In these treatment groups the organ clearance of vasopressin did not differ significantly from the controls. Each kidney is depicted and the different groups are represented by specific symbols.

$\pm 2.7 \mathrm{ml} / \mathrm{min}$ ). Cold was associated with marked vasoconstriction, and despite perfusing the kidneys at pressures $\cong 90 \mathrm{~mm} \mathrm{Hg}$ higher than the controls, the average flow $(31 \pm 0.5 \mathrm{ml} / \mathrm{min})$ remained significantly lower than that of the controls.

\section{DISCUSSION}

The earlier work on the renal handling of vasopressin yielded conflicting reports that have resulted in considerable confusion. (See review of Lauson [1]). These conflicting reports have been a consequence of several factors including the use of relatively unreliable bioassay procedures. Recently, with the advent of sensitive radioimmunoassays for vasopressin $(7-10)$, much of the difficulty in studying vasopressin metabolism has been resolved. In the present study, the antibody used in the radioimmunoassay was specific for AVP to the extent that it has been tested; possible metabolites of AVP have not been tested. Furthermore, as synthetic AVP was the sole peptide added to the perfusion medium, we were assured that only immuno- reactive AVP and possibly also immunoreactive fragments thereof were measured. It is possible that the kidney may release immunoreactive fragments into the perfusate or the urine which would result in some error, probably small, in the calculated AVP clearances. If present in the perfusate these fragments would result in an underestimation of the organ clearance and peritubular clearance of AVP; if present in the urine only, an overestimation of urinary clearance would occur. Nevertheless, even if this did occur it would not alter the validity of our overall description of the manner in which the isolated kidney handles AVP. It is also possible that all the intact AVP removed is degraded within the kidney to small fragments without the release of hypothetical immunoreactive fragments into perfusate or urine. Our calculations would then accurately reflect the true clearance of immunoreactive intact AVP. A further consideration is the possibility that the kidney may modify the structure of AVP with loss of immunoreactivity, but not biological activity. There is however no documented evidence that such a process occurs.

In the past there has been considerable controversy regarding the question of whether or not AVP binds to plasma proteins $(1,11)$. By showing that AVP does not bind appreciably to the albumin perfusing the isolated kidney, interpretation of our data has been simplified. Thus it is reasonable to assume that AVP (mol wt 1,084 ) passes through the glomerular filtration barrier with little hindrance, and that the glomerular clearance of AVP approximates the GFR. As the GFR in the control kidneys was less than half the $\mathrm{OC}_{\mathrm{AVP}}$, it is apparent that filtration cannot account for all the AVP cleared by the kidney and that peritubular clearance must play a major role in the clearance of the hormone. AVP leaving the peritubular circulation could theoretically be removed from the renal interstitium by tubular cells or by lymphatic drainage. However, as lymph from the isolated kidney drains into the perfusion medium, lymphatic drainage cannot account for the AVP leaving the peritubular circulation. This suggests that uptake by the contraluminal aspect of the tubular cells occurs. It is likely that at least part of the AVP cleared from the peritubular compartment binds to specific receptors on the contraluminal plasma membranes of the distal tubule and collecting ducts with subsequent activation of vasopressin-sensitive adenylate cyclase at this site (12-15). Apart from serving to stimulate the formation of cyclic-AMP, the AVP removed from the peritubular compartment is probably degraded by the rich supply of enzymes present in the plasma membrane (16) and in the cell (1719). Although there is no evidence in support thereof, it is conceivable that the hormone may be returned to the circulation after undergoing a minor structural modification without loss of biological activity, but with 
loss of immunoreactivity, and hence not measured in this study. It is also possible that some of the AVP is transported intact across the tubular cells and secreted into the tubular lumen $(20,21)$.

Further evidence suggesting that peritubular clearance plays a major role in the removal of immunoreactive AVP by the isolated rat kidney is provided by the observation that under certain conditions, despite a marked fall in GFR, the perfused kidney maintains a constant rate of AVP clearance. In this respect, the kidney handles AVP in the same manner as it does insulin, a polypeptide of mol wt 6,000 (22). Although difficult to explain, there are several possible mechanisms for this observation. Based on histochemical studies, Venkatachalam and Karnovsky (23) have suggested that the intrarenal distribution of protein leaving the peritubular vessels may depend on regional rates of tubular fluid reabsorption, bulk outward flow of water tending to wash the proteins toward the capillaries. It is therefore conceivable that the fall in bulk flow associated with a drop in GFR may enhance the peritubular clearance of AVP, accounting for the con-

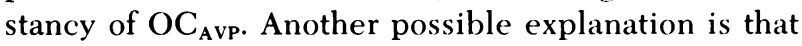
contraluminal uptake may be regulated in part by the amount of AVP presented to and taken up by the luminal surface of the tubular cell. Thus when the filtered load drops, more AVP is extracted from the peritubular compartment. Constancy of $\mathrm{OC}_{\mathrm{AvP}}$ at varying glomerular filtration rates would also occur if AVP were poorly filtered and removal were solely by peritubular clearance. However, as discussed earlier, AVP probably passes through the glomerular barrier with little restriction. Finally, if all the filtered AVP were reabsorbed and returned unaltered to the peritubular circulation, then a drop in GFR would not affect the $\mathrm{OC}_{\mathrm{Avp}}$. This is unlikely in view of the rich supply of AVP degrading enzymes in the kidney $(17,18)$.

The possibility of peritubular clearance of AVP has previously been raised by Ginsburg (20) and by Harvey et al. (21). However, the findings of Lauson et al. (24) were not in agreement, for they reported that the total renal AVP clearance in dogs was slightly less than the GFR. In these earlier studies AVP was measured by bioassay. With a sensitive radioimmunoassay, which correlated closely with the bioassay, Shade and Share (25) found that at physiological plasma antidiuretic hormone levels and at normal renal plasma flows the total renal clearance of antidiuretic hormone in dogs was equal to the GFR and that the urinary AVP clearance averaged $59 \%$ of the GFR. However, when renal plasma flow was reduced to $25 \%$ of control levels, despite the cessation of glomerular filtration, renal AVP clearance only fell to $20 \%$ of the control values, suggesting the presence of a postglomerular mechanism for clearing AVP.

In the present study, only $18 \%$ of the total amount of AVP removed by the control kidneys was excreted in the urine, the balance presumably being degraded within the kidney (19). Fractional excretion of AVP was $38 \%$ of the filtered load, indicating that AVP is removed from the tubular lumen. Theoretically, luminal removal could be achieved in several ways including transport into the peritubular fluid of intact AVP, absorption across the luminal membrane with intracellular degradation, degradation by the luminal plasma membrane or degradation by luminal fluid with reabsorption, or excretion of the degradation products. As with other peptides $(26,27)$, absorption of intact AVP and any products of degradation would be expected to take place in the proximal tubule and not in the distal nephron where, as discussed earlier, contraluminal uptake of AVP may occur. Absorbed AVP is presumably degraded within the tubular cells; transtubular transport of intact hormone being unlikely in view of the active AVP degrading system in the kidney (18). Although the exact fate of filtered AVP is not known, the report by Walters and Bowman (19) and the review of Lauson (1) suggest that degradation occurs beyond the proximal tubule, possibly by the action of a distal luminal membrane-bound enzyme. Clearly further studies are indicated to determine how the tubules handle filtered AVP.

Having established that both the luminal and the contraluminal aspect of the tubular cells are exposed to the AVP cleared from the renal circulation, we examined various factors that might affect the removal of the peptide by these two surfaces of the cells. In interpreting the results obtained, it should be recognized that we have made two assumptions: (a) that the various maneuvers employed do not alter the impermeability of the luminal membrane to inulin and (b) that in the presence of a normally functioning luminal mechanism for removing AVP, urinary clearance of AVP will fall in proportion to a fall in GFR, and fractional excretion of filtered AVP will remain constant, as occurred in our glucose-free and ouabain experiments. As to luminal impermeability to inulin, microperfusion studies carried out in vivo (28) and in vitro $(29,30)$ indicate that luminal impermeability to inulin is not altered by inhibition of oxidative metabolism, cold $\left(21^{\circ} \mathrm{C}\right)$, ouabain $(0.1 \mathrm{mM})$, or the absence of glucose. Hence it is likely that luminal impermeability to inulin was maintained under the various conditions employed in our study. Regarding the luminal handling of AVP, anoxia and cold appeared to increase the fractional excretion of filtered AVP, which was not significantly affected by the absence of exogenous glucose, high levels of AVP or ouabain. As it has been shown that the degradation of AVP by tissue homogenates is independent of oxygen (17), it appears that the increased fractional excretion of filtered AVP by the anoxic kidneys was a consequence of a depression of 
a reabsorptive rather than a degradation process. Cold, which may inhibit enzyme activity and also transport processes, may have increased fractional excretion of filtered AVP by depressing degradation and reabsorption. These findings are similar to those observed in studies on the handling of low molecular weight proteins $(31,22)$ (lysozyme and insulin) by the isolated perfused rat kidney. Similarly, Miller et al. (32) found that the luminal uptake of horseradish peroxidase ( $\mathrm{mol}$ wt, 40,000) was abolished by cold and by interference with oxidative metabolism, but not by the absence of exogenous fuels. These workers also found that ouabain inhibited the luminal uptake of horseradish peroxidase, whereas in our study ouabain did not interfere with the fractional excretion of AVP, suggesting that small peptides are handled in a manner different to that of larger proteins. The possibility that inhibition of luminal removal of AVP in the presence of cold or anoxia might be secondary to the inhibition of sodium transport and not a result of a direct effect on a metabolic energy-dependent transport process is worthy of consideration. However, in the kidneys perfused without glucose or in those perfused with ouabain, fractional excretion of filtered sodium increased significantly in the absence of a significant increase in the fractional excretion of filtered AVP, suggesting that at least in part luminal AVP reabsorption is not linked to sodium reabsorption.

Extending our observations to the contraluminal aspect of the tubular cell, we found that contraluminal uptake is also sensitive to cold, being virtually abolished at $10^{\circ} \mathrm{C}$, and that this process does not require exogenous glucose as a fuel. In contrast to its effect on the luminal uptake of AVP, anoxia did not inhibit contraluminal uptake. On the contrary, although GFR fell to $8 \%$ of the $\mathrm{OC}_{\mathrm{AVP}}$ in the absence of oxygen, peritubular clearance increased and the $\mathrm{OC}_{\mathrm{AVP}}$ was maintained at control levels. This suggests that contraluminal uptake is not dependent on oxidative metabolism and, furthermore, that peritubular clearance of AVP is able to increase in proportion to the fall in glomerular clearance of AVP and so maintain a relatively constant $\mathrm{OC}_{\mathrm{AVP}}$.

The ability of the kidney to clear AVP from the peritubular circulation and maintain the $\mathrm{OC}_{\mathrm{AVP}}$ at control levels was impaired by high levels of AVP and by cold. High levels of AVP, although not interfering with luminal uptake, may have impaired contraluminal uptake by saturating contraluminal AVP degradation, transport, or receptor binding. Cold may also have inhibited contraluminal uptake by inhibiting AVP degradation, transport, or receptor binding (14). In addition, as both AVP and cold are vasoactive agents, it is possible that a redistribution of intrarenal perfusate flow (33) may have impaired AVP clearance from the peritubular circulation.
The data presented in this study indicate that AVP is removed by the tubular cells from the lumen of the tubules and from the peritubular compartment. In addition the study suggests that removal of AVP is a temperature-dependent process consisting of two different systems. The one system that is associated with the luminal aspect of the cell is not depressed by high concentrations of AVP, but may possibly depend on oxidative metabolism. The other system associated with the contraluminal aspect of the tubular cell does not appear to require oxidative metabolism but is depressed by high concentrations of AVP. It is noteworthy that under several conditions when GFR falls, decreasing the amount of AVP cleared by filtration and thus the load of AVP handled by the luminal aspect of the cell, peritubular clearance increases and the rate at which the kidney clears AVP remains constant.

In interpreting the data presented in this study, recognition must be made of the differences between renal function in the isolated organ and in the intact animal. In the isolated kidney GFR is reduced, whereas perfusion flow is several fold greater than in vivo, a situation that might tend to exaggerate events on the contraluminal aspect of the tubules and also reduce the role of filtration. Thus, the role of peritubular AVP clearance would probably be exaggerated and that of glomerular AVP clearance reduced. In addition to a species difference this may account for the quantitative difference noted earlier, between the renal handling of AVP in the intact dog and the isolated rat kidney. Nevertheless, the isolated perfused rat kidney has allowed an approach to studying the renal handling of AVP under a variety of conditions and in particular has permitted the study of peritubular events. This has resulted in the unequivocal demonstration of a peritubular mechanism for AVP removal that differs from that of the luminal mechanism.

\section{ACKNOWLEDGMENTS}

We gratefully acknowledge the technical assistance of Don Miles and the secretarial assistance of Martha Perser and Joanne Brown.

This study was supported by grants in aid from the American Heart Association (76-876), with funds contributed in part by the Tennessee Heart Association, and grants AM19774-01 and HL12990 from the U. S. Public Health Service. Computer assistance was supported by U. S. Public Health Service grant HL-09495.

\section{REFERENCES}

1. Lauson, H. D. 1974. Metabolism of the neurohypophysial hormones. Handb. Physiol. 4(Sect. 7. Endocrinology): 287-393.

2. Nishiitsutsuji-Uwo, J. M., B. D. Ross, and H. A. Krebs. 1967. Metabolic activities of the isolated perfused rat kidney. Biochem. J. 103: 852-862.

3. Ross, B. D., F. H. Epstein, and A. Leaf. 1973. Sodium 
reabsorption in the perfused rat kidney. Am. J. Physiol. 225: 1165-1171.

4. Shade, R., and L. Share. 1976. Metabolic clearance of immunoreactive vasopressin and immunoreactive [ $\left.{ }^{131} \mathrm{I}\right]-$ iodo vasopressin in the hypophysectomized dog. Endocrinology. 99: 1199-1206.

5. Mortimore, G. E., F. Tietze, and D. Stetten, Jr. 1959. Metabolism of Insulin-I ${ }^{131}$. Studies in isolated, perfused rat liver and hindlimb preparations. Diabetes. 8: 307-314.

6. Kirk, R. E. 1968. Experimental Design: Procedures for the behavioral sciences. Roger E. Kirk, editor. Wadsworth Publishing Co., Belmont, Calif. 93-94.

7. Robertson, G. L., L. A. Klein, J. Roth, and P. Gorden. 1970. Immunoassay of plasma vasopressin in man. Proc. Natl. Acad. Sci. U. S. A. 66: 1298-1305.

8. Beardwell, C. G. 1971. Radioimmunoassay of arginine vasopressin in human plasma.J. Clin. Endocrinol. Metab. 33: $254-260$.

9. Robertson, G. L., E. A. Mahr, S. Athar, and T. Sinha. 1973. Development and clinical application of a new method for the radioimmunoassay of arginine vasopressin in human plasma. J. Clin. Invest. 52: 2340-2352.

10. Husain, M. K., N. Fernando, M. Shapiro, A. Kagan, and S. M. Glick. 1973. Radioimmunoassay of arginine vasopressin in human plasma. J. Clin. Endocrinol. Metab. 37: 616-625.

11. Baumann, G., and J. F. Dingman. 1976. Distribution, blood transport, and degradation of antidiuretic hormone in man. J. Clin. Invest. 57: 1109-1116.

12. Dousa, T., O. Hechter, I. L. Schwartz, and R. Walter. 1971. Neurohypophyseal hormone-responsive adenylate cyclase from mammalian kidney. Proc. Natl. Acad. Sci. U. S. A. 68: 1693-1697.

13. Campbell, B. J., G. Woodward, and V. Borberg. 1972. Calcium-mediated interactions between the antidiuretic hormone and renal plasma membranes. J. Biol. Chem. 247: 6167-6175.

14. Bockaert, J., C. Roy, R. Rajerison, and S. Jard. 1973. Specific binding of $\left[{ }^{3} \mathrm{H}\right]$ lysine-vasopressin to pig kidney plasma membranes. J. Biol. Chem. 248: 5922-5931.

15. Rajerison, R., J. Marchetti, C. Roy, J. Bockaert, and S. Jard. 1974. The vasopressin-sensitive adenylate cyclase of the rat kidney. J. Biol. Chem. 249: 6390-6400.

16. Musolan, C., and B. J. Campbell. 1975. Inactivation of antidiuretic hormone by plasma membranes isolated from porcine kidney medulla. Rev. Roum. Biochim. 12: 47-52.

17. Dicker, S. E., and A. L. Greenbaum. 1956. Inactivation of the antidiuretic activity of vasopressin by tissue homogenates. J. Physiol. (Lond.). 132: 199-212.

18. Walter, R., and H, Shlank. 1975. Differences in the en- zymatic inactivation of arginine vasopressin and oxytocin by rat kidney homogenate. Endocrinology. 96: 811-814.

19. Walter, R., and R. H. Bowman. 1973. Mechanism of inactivation of vasopressin and oxytocin by the isolated perfused rat kidney. Endocrinology. 92: 189-193.

20. Ginsburg, M. 1957. The clearance of vasopressin from the splanchnic vascular area and the kidneys. J. Endocrinol. 16: 217-226.

21. Harvey, N., J. J. Jones, and J. Lee. 1967. The renal clearance and plasma binding of vasopressin in the dog. J. Endocrinol. 38: 163-171.

22. Rabkin, R., and A. E. Kitabchi. 1978. Factors influencing the handling of insulin by the isolated rat kidney. J. Clin. Invest. 61: 169-175.

23. Venkatachalam, M. A., and M. J. Karnovsky. 1972. Extravascular protein in the kidney. An ultrastructural study of its relation to renal peritubular capillary permeability using protein tracers. Lab. Invest. 27: 435-444.

24. Lauson, H. D., M. Bocanegra, and C. F. Beuzeville. 1965. Hepatic and renal clearance of vasopressin from plasma of dogs. Am. J. Physiol. 209: 199-214.

25. Shade, R. E., and L. Share. 1977. Renal vasopressin clearance with reductions in renal blood flow in the dog. Am. J. Physiol. 1: F341-F347.

26. Pullman, T. N., S. Oparil, and F. A. Carone. 1973. Fate of labeled angiotensin II microinfused into individual nephrons in the rat. Am. J. Physiol. 228: 747-751.

27. Carone, F. A., T. N. Pullman, S. Oparil, and S. Nakamura. 1976. Micropuncture evidence of rapid hydrolysis of bradykinin by rat proximal tubule. Am. J. Physiol. 230: 1420-1424.

28. Green, R., and G. Giebisch. 1975. Ionic requirements of proximal tubular sodium transport. I. Bicarbonate and chloride. Am. J. Physiol. 229: 1205-1215.

29. Schafer, J. A., S. L. Troutman, M. L. Watkins, and T. E. Andreoli. 1978. Volume absorption in the pars recta. I. "Simple" active $\mathrm{Na}^{+}$transport. Am. J. Physiol. 3: F332F339.

30. Schafer, J. A., C. S. Patlak, and T. E. Andreoli. 1975. A component of fluid absorption linked to passive ion flows in the superficial pars recta. J. Gen. Physiol. 66: 445471.

31. Maack, T. 1975. Renal handling of low molecular weight proteins. Am. J. Med. 58: 57-64.

32. Miller, A. T., D. M. Hale, and K. D. Alexander. 1965. Histochemical studies on the uptake of horseradish by rat kidney slices. J. Cell Biol. 27: 305-312.

33. Johnson, M. D., C. S. Park, and R. L. Malvin. 1977. Antidiuretic hormone and the distribution of renal cortical blood flow. Am. J. Physiol. 232: F111-F116. 